\title{
Alginate Biocomposite Films Incorporated with Cinnamon Essential Oil Nanoemulsions: Physical, Mechanical, and Antibacterial Properties
}

\author{
Kporwodu Frank, ${ }^{1}$ Coralia V. Garcia ${ }^{(D)},{ }^{1}$ Gye Hwa Shin ${ }^{(D)},{ }^{2}$ and Jun Tae Kim ${ }^{1}{ }^{1}$ \\ ${ }^{1}$ Department of Food Science and Technology, Keimyung University, Daegu 42601, Republic of Korea \\ ${ }^{2}$ Department of Food and Nutrition, Kunsan National University, Gunsan 54150, Republic of Korea \\ Correspondence should be addressed to Jun Tae Kim; jtkim92@kmu.ac.kr
}

Received 15 October 2018; Accepted 22 November 2018; Published 19 December 2018

Academic Editor: Cornelia Vasile

Copyright (c) 2018 Kporwodu Frank et al. This is an open access article distributed under the Creative Commons Attribution License, which permits unrestricted use, distribution, and reproduction in any medium, provided the original work is properly cited.

\begin{abstract}
Alginate-based antibacterial biocomposite films were prepared by incorporating with cinnamon essential oil nanoemulsions (CEO$\mathrm{NE}$ ). CEO-NE was first prepared by mixing and homogenizing the oil phase and aqueous phase containing polysorbate 80 (Tween 80), using a probe-type ultrasonication equipment. The biocomposite films were then prepared by incorporating the CEO-NE to an aqueous solution of alginate and glycerol, homogenizing, casting, and drying. The mean droplet size, zeta potential, and polydispersity index of the CEO-NE were $92.2 \mathrm{~nm},-15.58 \mathrm{mV}$, and 0.25 , respectively. Young's modulus of the CEO-NE/alginate biocomposite films was significantly increased with an increasing concentration of CEO-NE, while their elongation at break was significantly decreased. However, the tensile strength of the CEO-NE/alginate biocomposite films was not significantly changed. The maximum tensile strength and elongation at break of the biocomposite films were $15.63 \mathrm{MPa}$ and $23.67 \%$, respectively, corresponding to the biocomposite films containing 20\% CEO-NE. The biocomposite films containing 20\% CEO-NE also showed strong antibacterial effects against Salmonella typhimurium, Bacillus cereus, Escherichia coli, and Staphylococcus aureus, achieving inhibition zones from 29.7 to $53.0 \mathrm{~mm}$. These results show the potential of the CEO-NE/alginate biocomposite films as antibacterial packaging for extending the shelf life of fresh foods.
\end{abstract}

\section{Introduction}

Active packaging has been defined as films or containers incorporating certain active compounds to maintain and extend the shelf-life of a food product [1]. Examples of active packaging include polysaccharide-based biodegradable and edible films and composites that could be used as carriers of active compounds such as antimicrobials, antioxidants, and texture enhancers [2-4]. In addition, these films not only protect foods from dehydration but also act as a gas barrier against the surrounding media $[1,2]$. Natural polysaccharides have been used in both medical and food processing applications because of their biodegradability, biocompatibility, and interactions with drugs and foods [4]. Nevertheless, although biopolymer-based films showed excellent gas barrier properties, they exhibited poor water resistance because of their hydrophilic nature $[5,6]$.

Alginates are natural polymers extracted from brown seaweed and are composed of 1-4- $\beta$-D-mannuronic acid and $\alpha$-L-guluronic acid. It has been commonly known that alginates can be cross-linked with a tridimensional network by a reaction with polyvalent metal cations, specifically calcium ions $[5,6]$. Since alginate films have a hydrophilic feature, cross-linking with calcium ions has been performed to improve their mechanical strength and water barrier properties [6]. Essential oils have also been incorporated into the alginate film to improve its water barrier properties and antibacterial activities [5, 7].

Essential oils (EOs) have widespread use as flavoring materials and are also used widely in the nutritional, pharmaceutical, and agricultural fields for their reported 
antibacterial and antioxidant properties [8, 9]. Thus, they could be incorporated into the packaging material or used as edible coatings to extend the shelf-life of foods. Cinnamon essential oil (CEO) is one of the most effective antibacterial oils; its major component is cinnamaldehyde, having minimum inhibitory concentrations (MIC) of $0.05-5 \mu \mathrm{L} / \mathrm{mL}$ in vitro [8]. Cinnamon is not harmful when consumed in food products, and it is proven to inhibit the growth of molds, yeast, and bacteria [9]. However, when preparing biocomposite films, direct addition of the hydrophobic cinnamon oil to the hydrophilic alginate may result in a film-forming solution that is not uniform and exhibits some phase separation; hence, in this study, cinnamon oil was first incorporated into a nanoemulsion system.

Nanoemulsions have been defined as emulsions with a droplet size in the range of $20-200 \mathrm{~nm}[10,11]$. Recent investigations suggest that EO-loaded nanoemulsions exhibit better physical and antibacterial properties than do conventional emulsions [12-14]. The small particle size of nanoemulsions has been reported to increase the surface area per unit of mass of lipophilic compounds, thereby enhancing their physicochemical properties, stability, and biological activities $[14,15]$. Therefore, the current study is aimed at developing biocomposite alginate-based films incorporated with CEO-NE as a potential food packaging material. The physical, mechanical, and antibacterial properties of the films were also evaluated.

\section{Materials and Methods}

2.1. Materials. Sodium alginate, agar, Tween 80 , and glycerol were purchased from Duksan Pure Chemicals (Ansan, Korea). Cinnamon essential oil (CEO; Cinnamomum zeylanicum) was purchased from NOW Foods Company (Bloomingdale, IL, USA). Nutrient broth was obtained from Becton Dickinson and Company (Franklin Lakes, NJ, USA). Staphylococcus aureus (ATCC 6538P), Streptococcus mutans (ATCC 25175), Bacillus cereus (ATCC11778), Escherichia coli (ATCC 8739), Listeria monocytogenes (ATCC 19115), and Salmonella typhimurium (KCCM 11862) were obtained from Sigma-Aldrich (St. Louis, MO, USA).

2.2. GC-MS Analysis of CEO. Gas chromatography-mass spectrometry (GC-MS) analysis of the CEO was performed on an Agilent 7890B-5977B system (Palo Alto, CA, USA) fitted with an Agilent J\&W DB-5 column $(30 \mathrm{~m} \times 0.25 \mathrm{~mm}$, $0.25 \mu \mathrm{m})$. The temperature program started at $60^{\circ} \mathrm{C}$ for $1 \mathrm{~min}$, increased at a rate of $4^{\circ} \mathrm{C} / \mathrm{min}$ to $280^{\circ} \mathrm{C}$, and held at this temperature for $5 \mathrm{~min}$. The injector and ion source were kept at 250 and $230^{\circ} \mathrm{C}$, respectively. The carrier gas was helium, pumped at a flow rate of $1 \mathrm{~mL} / \mathrm{min}$. The sample $(1 \mu \mathrm{L})$ was injected in split mode at a 50:1 split ratio. Mass spectra were obtained by electron impact ionization (EI) at $70 \mathrm{eV}$. The total ion current (TIC) in the range $30-600 \mathrm{~m} / z$ was collected. Essential oil components were tentatively identified by comparison of their mass spectra with those stored in the mass spectral library of the GC-MS system and semiquantified as percentage of the total peak area.
2.3. Preparation of CEO Nanoemulsions (CEO-NE). CEOloaded nanoemulsions were prepared as follows. Coarse emulsions were first prepared by mixing CEO and an aqueous phase containing Tween 80 . CEO concentrations of 1 , $2,3,4$, and $5 \%(v / v)$ were used. Tween 80 was used at the same concentration as CEO. The mixture was vortexed for 2 min and further mixed under high-speed homogenization (WiseTis ${ }^{\circledR}$ HG-15D, DAIHAN Scientific, Seoul, Korea)) at $5000 \mathrm{rpm}$ for $10 \mathrm{~min}$. Then, the CEO nanoemulsions (CEO-NE) were obtained from the coarse emulsions by ultrasonication at 750 watts, $40 \%$ amplitude for 10 min using a Sonics Vibra-Cell ${ }^{\mathrm{TM}}$ (VC 750, Newtown, CT, USA).

2.4. Droplet Size, Polydispersity Index (PDI), and Zeta Potential of CEO-NE. The mean droplet size, polydispersity index (PDI), and zeta potential of the CEO-NE were measured by dynamic light scattering (DLS), using a zeta potential and particle size analyzer (ELSZ-1000, Otsuka Electronics, Tokyo, Japan). A $1 \mathrm{~mL}$ sample was loaded onto a polystyrene latex cell, and the mean droplet size and PDI were measured at $25^{\circ} \mathrm{C}$, detector angle of $90^{\circ}$, and wavelength of $633 \mathrm{~nm}$. Each sample was measured at least 3 times, and the average values were used.

2.5. Preparation of CEO-NE/Alginate Biocomposite Films. Sodium alginate $(4 \mathrm{~g})$ was dispersed in $200 \mathrm{~mL}$ distilled water, and $20 \%$ ( $w / w$, based on alginate) glycerol was added as a plasticizer to avoid the brittleness of the films. To achieve complete dispersion, the mixture was stirred constantly at room temperature overnight using a magnetic stirrer at $300 \mathrm{rpm}$. To prepare the films, the nanoemulsion containing $4 \%(v / v)$ CEO was added to the alginate suspension in ratios from 20 to $40 \% \quad(v / w$ alginate solution). The mixtures were subjected to high-speed homogenization at $8000 \mathrm{rpm}$ for $10 \mathrm{~min}$ to obtain the filmforming solution. An alginate film-forming solution without CEO was used as a control. The film-forming solutions were degassed and cast on a Teflon-coated glass plate. Then, the solutions were dried at $35^{\circ} \mathrm{C}$ in an oven for $24 \mathrm{~h}$. The dried films were further conditioned at $25^{\circ} \mathrm{C}$ and $50 \% \mathrm{RH}$ for $48 \mathrm{~h}$ before evaluation.

2.6. Color of the Biocomposite Films. The color of the biocomposite films was determined with a chroma meter (CR-400, Minolta, Tokyo, Japan). Film specimens were placed on a white standard plate $\left(L^{*}=96.85, a^{*}=0.01\right.$, and $\left.b^{*}=1.64\right)$, and the lightness $(L)$ and chromaticity parameters $a$ (redgreen) and $b$ (yellow-blue) were measured. Three readings on different sites of each film were recorded, and the average values were used. The total color difference $(\Delta E)$ was determined as follows [16]:

$$
\Delta E=\sqrt{\left(L^{*}-L\right)^{2}+\left(a^{*}-a\right)^{2}+\left(b^{*}-b\right)^{2}}
$$

where $L^{*}, a^{*}$, and $b^{*}$ are the color parameter values of the standard and $L, a$, and $b$ are the color parameter values of the film sample. 
2.7. Moisture Content. The moisture content of the biocomposite films was determined through the weight loss undergone by the film after $24 \mathrm{~h}$ of oven drying at $90^{\circ} \mathrm{C}$ until a constant dry weight was obtained. This temperature was chosen to avoid loss of CEO and plasticizer [16].

2.8. Mechanical Properties. The film thickness was measured using a manual digital micrometer (MDC-25MJ, Mitutoyo Co., Kanagawa, Japan) to the nearest $0.001 \mathrm{~mm}$. Measurements were made in 10 random locations for each film, and an average value was calculated. The mechanical properties of the biocomposite films were tested using a universal testing machine (UTM; Zwick Z010TN, Zwick GmbH \& Co. KG, Ulm, Germany) according to the ASTM D882 standard method [17] with some modifications. First, films were cut in rectangular strips of $10 \times 80 \mathrm{~mm}$ and preconditioned for $48 \mathrm{~h}$ at $25^{\circ} \mathrm{C}$ and $50 \% \mathrm{RH}$ before evaluation. The films were clamped between grips, and then force and deformation were recorded during extension. The grip distance was $50 \mathrm{~mm}$, and the strain rate was $50 \mathrm{~m} / \mathrm{min}$. Tensile strength, elongation at break, and Young's modulus of the biocomposite films were measured according to ASTM D882 [17].

2.9. Scanning Electron Microscopy (SEM). The microstructure of the biocomposite film's fractured surface obtained during the mechanical analysis was examined using a scanning electron microscope (Hitachi S-4800 FE-SEM, Hitachi Ltd., Tokyo, Japan) with an acceleration voltage of $3.0 \mathrm{kV}$. The films were mounted on the specimen holder using a carbon tape and sputtered with a thin layer of osmium coating for $1 \mathrm{~s}$ using a plasma osmium coater (OPC-60A, West Chester, PA, USA).

2.10. Antibacterial Activity of CEO-NEs and Biocomposite Films. The disc diffusion method was used to investigate the antibacterial activity of the CEO-NE according to published methods with some modifications $[18,19]$. Bacterial suspension at $10^{8} \mathrm{CFU} / \mathrm{mL}$ was spread over the plates containing nutrient agar medium. The paper discs were aseptically placed on the inoculated medium surface; $30 \mu \mathrm{L}$ of CEO-NE was added and left for $30 \mathrm{~min}$ at room temperature for sufficient oil diffusion before incubation at $37^{\circ} \mathrm{C}$ for $24 \mathrm{~h}$. The inhibition zone was then measured.

Antibacterial activity testing of the CEO-NE/alginate biocomposite films was also carried out using the disc diffusion (inhibition zone) method with some modifications [20]. The films were cut into $18 \mathrm{~mm}$ circular shapes and then aseptically placed on nutrient broth-agar plates previously inoculated with $0.15 \mathrm{~mL}$ of test bacteria $\left(10^{8} \mathrm{CFU} / \mathrm{mL}\right)$. The plates were then incubated at $37^{\circ} \mathrm{C}$ for $24 \mathrm{~h}$. Observations on the diagonal of the inhibitory zone surrounding the films and contact area between the film and medium surface were made.

2.11. Statistical Analysis. Measurements of particle characterization, color, mechanical properties, and antibacterial activity were performed in triplicate, and data are expressed as mean \pm standard deviation (SD). Statistical analysis was performed using SPSS version 20.0 (SPSS Inc., Chicago, IL,
USA). Significant differences among treatments were determined by analysis of variance (ANOVA) and Duncan's multiple range test. The level of significance was set at $p<0.05$.

\section{Results and Discussion}

3.1. Composition of the CEO. GC-MS analysis revealed that the main component in the CEO was $(E)$-cinnamaldehyde, representing $60.99 \%$ of the total peak area. This result was expected as cinnamaldehyde is known to be the major component of cinnamon oil. Other major compounds in the CEO were cinnamaldehyde dimethyl acetal (10.48\%), eugenol $(5.36 \%)$, which is also known for its antibacterial effects, and caryophyllene (4.26\%). The composition of the CEO is summarized in Table 1.

3.2. Characterization of the CEO-NE. The effects of the CEO concentration on the mean droplet size, PDI, and zeta potential of the CEO-NE are displayed in Figure 1. These parameters have been shown to have a crucial effect on the color and mechanical properties of edible films [15]. The mean droplet size of the CEO-NE significantly $(p<0.05)$ increased with increasing oil concentration, with the smallest droplet size $(55.8 \mathrm{~nm})$ obtained at $1 \%(v / v)$ essential oil (Figure 1(a)). Small nanoparticles $<200 \mathrm{~nm}$ are desirable because of their enhanced properties and also result in smooth and stable films $[21,22]$. The PDI value has been defined as the measure of heterogeneity in the droplet size distribution. PDI values close to 0 indicate homogeneous size distributions, whereas PDI values close to 1 indicate heterogeneous size distributions [15]. The PDI obtained in this study ranged between 0.16 and 0.26 , showing that the CEONE obtained was homogeneous.

The zeta potential of the CEO-NE is shown in Figure 1(b). The zeta potentials of the CEO-NE ranged between -15.16 and $-28.74 \mathrm{mV}$. Even though the nonionic surfactant Tween 80 was used, the CEO-NE droplets exhibited a highly negative zeta potential, which can be attributed to the adsorption of anionic fatty acid molecules of the oil phase [15]. Furthermore, the CEO-NE hindered the growth of both $S$. aureus and E. coli bacteria, being particularly effective against the latter as observed in the size of the inhibition zones (13 and $20 \mathrm{~mm}$, respectively, for a concentration of $4 \% v / v$ ) (data not shown).

3.3. Mechanical Properties of the CEO-NE/Alginate Biocomposite Films. The mechanical properties of the CEO-NE/alginate biocomposite films were characterized by measuring the tensile strength (TS), percent elongation at break (EB), and Young's modulus (YM), which represent the stretch capacity, flexibility, and rigidity of the films, respectively. The results obtained are shown in Figure 2. The TS, EB, and YM of the control film were 15.6 MPa, 23.7\%, and 265.0 MPa, respectively. No significant $(p<0.05)$ differences between the TS of the CEO$\mathrm{NE}$ /alginate biocomposite films and control alginate films were observed. Although several studies have reported that essential oil addition to polymer-based film formulations tends to weaken the films by decreasing the cohesive 
TABle 1: Composition of the cinnamon essential oil. Compounds were tentatively identified by their mass spectra.

\begin{tabular}{|c|c|c|c|}
\hline Peak no. & Compound & $\begin{array}{l}\text { Retention } \\
\text { time (min) }\end{array}$ & $\begin{array}{c}\text { Peak } \\
\text { area (\%) }\end{array}$ \\
\hline 1 & 3-Thujene & 6.6 & 0.14 \\
\hline 2 & 2-Pinene & 6.8 & 0.63 \\
\hline 3 & Camphene & 7.3 & 0.25 \\
\hline 4 & Benzaldehyde & 7.6 & 0.36 \\
\hline 5 & $\beta$-Pinene & 8.1 & 0.25 \\
\hline 6 & $\alpha$-Phellandrene & 8.9 & 1.28 \\
\hline 7 & $\alpha$-Terpinene & 9.2 & 0.46 \\
\hline 8 & p-Cymene & 9.5 & 1.46 \\
\hline 9 & D-Limonene & 9.6 & 0.45 \\
\hline 10 & $\beta$-Phellandrene & 9.7 & 1.78 \\
\hline 11 & Terpinolene & 11.4 & 0.13 \\
\hline 12 & Linalool & 11.8 & 2.64 \\
\hline 13 & Benzenepropanal & 14.0 & 0.23 \\
\hline 14 & 3-Cyclohexen-1-ol & 14.6 & 0.18 \\
\hline 15 & 3-Cyclohexen-1-methanol & 15.1 & 0.43 \\
\hline 16 & (E)-Cinnamaldehyde & 18.1 & 60.99 \\
\hline 17 & 3-Phenylacrylaldehyde & 18.3 & 0.36 \\
\hline 18 & Eugenol & 20.3 & 5.36 \\
\hline 19 & $\alpha$-Copaene & 21.1 & 0.60 \\
\hline 20 & Cinnamaldehyde dimethyl acetal & 21.8 & 10.48 \\
\hline 21 & Caryophyllene & 22.6 & 4.26 \\
\hline 22 & (E)-Cinnamyl acetate & 23.3 & 3.57 \\
\hline 23 & $\alpha$-Humulene & 23.6 & 0.87 \\
\hline 24 & Phenol & 25.3 & 0.17 \\
\hline 25 & 2-Methoxycinnamaldehyde & 25.7 & 0.18 \\
\hline 26 & Caryophyllene oxide & 27.4 & 0.62 \\
\hline 27 & (E)-2-Dodecen-1-ol & 28.2 & 0.47 \\
\hline 28 & Benzoic acid & 32.4 & 1.12 \\
\hline
\end{tabular}

forces within the microstructure $[15,20,23]$, here we obtained resistant CEO-NE/alginate composite films. This result can be attributed to the plasticizing capacity of the oil [24]. The EB of the CEO-NE-alginate film decreased significantly $(p<0.05)$ as the amount of incorporated CEO-NE increased, whereas YM increased for low concentrations of CEO-NE but decreased when more than $30 \%$ CEO-NE was incorporated into the film. The decrease in YM may be explained by the decrease in the density and rigidity of the film matrix as more CEO-NE was incorporated $[24,25]$. The decrease in EB at high oil concentrations has been mentioned by some researchers [20], although other studies have reported the opposite [15, 23]. This lack of consistency in the results reported for $E$ $B$ may be due to the different interactions between the polymers and essential oils used to prepare the various films. Here, it is possible that the formation of discontinuities at high CEO-NE concentrations created stressed regions in the film matrix, leading to rupture, and thus decreased EB [26, 27].
3.4. Scanning Electron Microscopy (SEM). Micrographs of the fracture surface of the prepared films after break (postmechanical test) were taken to examine the effect of the nanodroplet organization along the biopolymer matrix on the film properties. The SEM images in Figure 3 correspond to the fracture surface of the alginate (control) film and those containing different concentrations of CEO-NE. The incorporation of CEO-NE at higher concentrations induced notable changes in the microstructure of the films as shown in Figures 3(d) and 3(e). The biocomposite films incorporated with CEO-NE exhibited a coarse appearance and large discontinuities or cavity-like structures, which can be attributed to the migration of oil droplets towards the surface of the film when in contact with air and further volatilization when water evaporates during film processing $[15,28]$. Moreover, at high CEO-NE concentrations, the surface area of the oil droplets increases, resulting in large pores or holes and leading to a heterogeneous biopolymer network formed between the lipophilic compounds and alginate, thereby decreasing chain-to-chain interactions [15].

3.5. Moisture Content and Color of the Biocomposite Films. Table 2 shows the moisture content and color parameters lightness $(L)$, red $(a)$, yellow $(b)$, and total color difference $(\Delta E)$ for the control (pure alginate) films and the biocomposite films containing different concentrations of CEO-NE. The control and biocomposite films with high CEO-NE content exhibited higher moisture contents than those with an intermediate amount of incorporated CEO-NE, although differences were small and the moisture content of the films remained at around $10 \%-12 \%$. Jouki et al. [16] attributed the increase in moisture content to the glycerol content in the film, whereas Ghasemlou et al. [23] considered that the moisture increase may be due to the hydrophobic nature of essential oils, which has a direct effect on the water retention of the films.

The control films appeared clear and transparent, whereas the addition of CEO-NE showed significant $(p<0.05)$ effects on the color and transparency of the films. The increase in the $b$ value reflects the increase in yellowness with higher CEO-NE concentrations. This result is similar to that reported for alginate-based films incorporating garlic oil [20]. The total color difference $(\Delta E)$ also increased as the amount of CEO-NE incorporated into the film increased. The decrease in $L$ values indicates that the films darkened with increasing CEO-NE concentration. This result was consistent with the previous reports where emulsified carrageenan and starch films became less transparent with the addition of essential oils [21,23]. This darkening effect has been attributed to the increase in diffuse reflectance caused by light scattering in the lipid droplets, which lowers both the light scattering intensity and whiteness index of the film [23]. Hence, the manufactured CEO-NE/ alginate biocomposite films became slightly yellow and tended to darken as more CEO-NE was incorporated.

3.6. Antibacterial Activity. CEO-NE incorporation into alginate resulted in biocomposite films with antibacterial activity. The inhibition zones increased significantly 


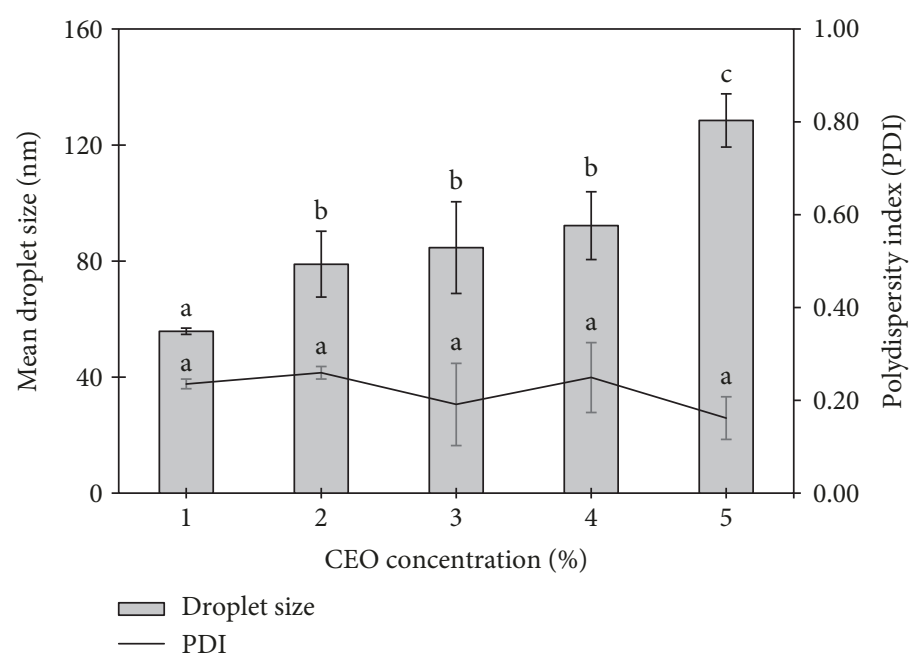

(a)

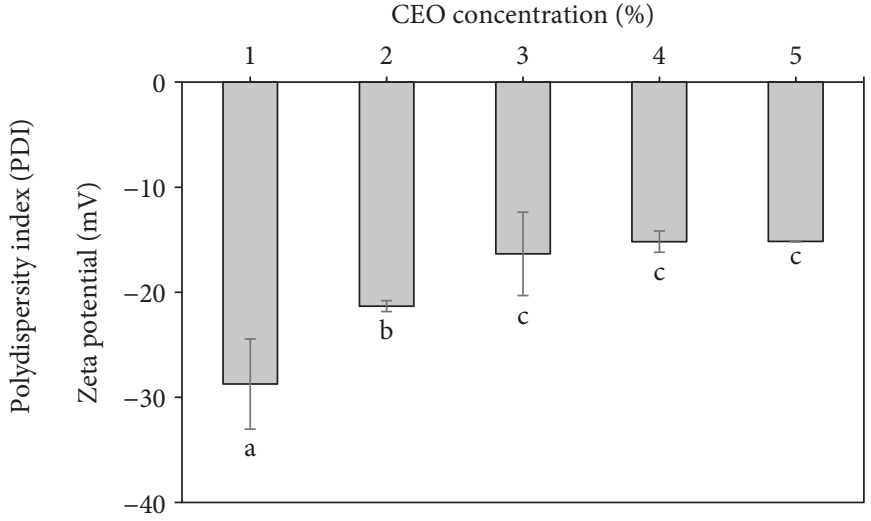

(b)

FIGURE 1: Effect of cinnamon essential oil (CEO) concentration on the (a) mean droplet size and PDI and (b) zeta potential of nanoemulsions (NEs). Different letters indicate a significant difference at $p<0.05$ by the ANOVA test. Error bars represent standard deviation $(n=3)$.

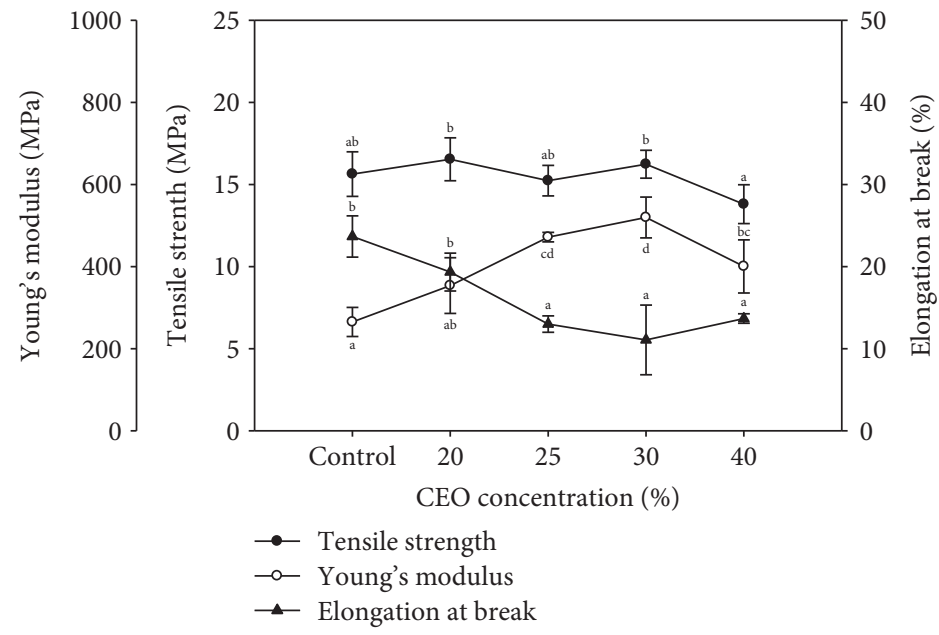

FIGURE 2: Tensile strength, elongation at break, and Young's modulus of pure alginate film and alginate films incorporating various CEO-NE concentrations. Different letters indicate a significant difference at $p<0.05$ by the ANOVA test. Error bars represent standard deviation $(n=3)$.

$(p<0.05)$ with increasing oil concentrations for the tested microorganisms (Table 3 and Figure 4). The CEO-NE/alginate biocomposite films were particularly effective against the Gram-negative S. typhimurium, which exhibited the largest inhibition halo among tested microorganisms, followed by the Gram-positive B. cereus and S. aureus. No antibacterial effect was observed for the control films. Several studies have shown that cinnamon has strong and consistent inhibitory effects against various food spoilage microorganisms [8]. Earlier studies have suggested that the antibacterial activity of cinnamon oil is mainly due to its major components cinnamaldehyde and cinnamic acid as well as to the presence of other compounds including carvacrol and eugenol $[8,9]$. Here, GC-MS analysis of the CEO used for the formulation revealed that cinnamaldehyde was the major compound in it and eugenol was also a major component. In addition, several terpenoids were also present in the CEO and could have also contributed to its antibacterial properties. The hydroxyl group of eugenol may react with proteins thereby inhibiting the action of enzymes, and hydrophobic compounds could also cause damage to the outer membrane of the Gram-negative bacterial cell wall, releasing lipopolysaccharides $[9,19,29]$. Reduction of intracellular ATP may be another explanation for the antibacterial activity [7]. Furthermore, the CEO mechanism of action against $S$. aureus may be due to the leakage of the intracellular potassium ions from the cells of the bacteria [29].

The inhibition zones obtained when using the films were also larger than those obtained with the CEO-NEs, which may be explained by the protective action of the polymer matrix against the rapid evaporation of the essential oil as 


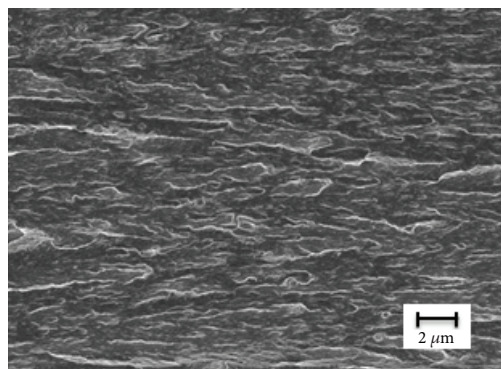

(a)

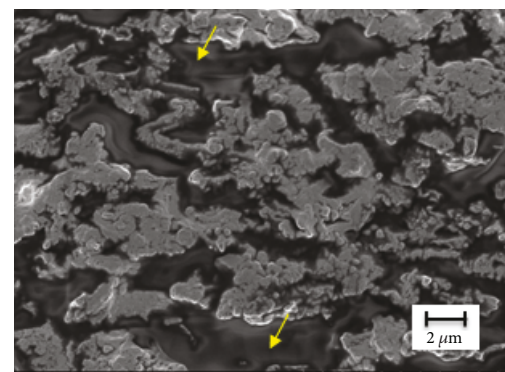

(b)

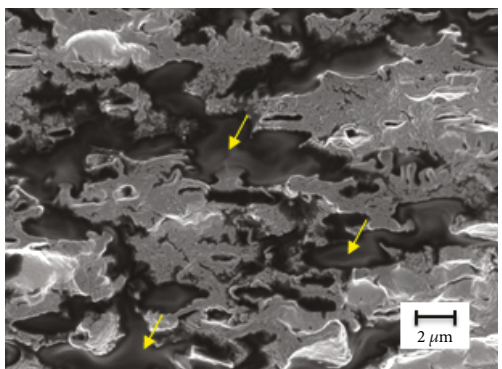

(c)

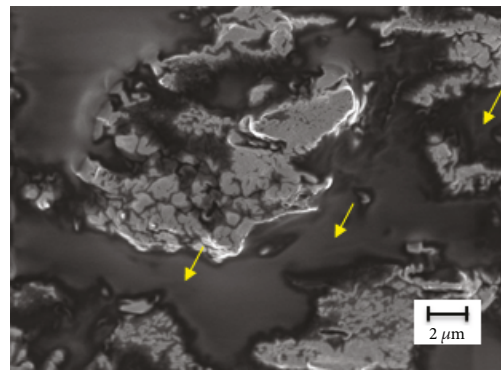

(d)

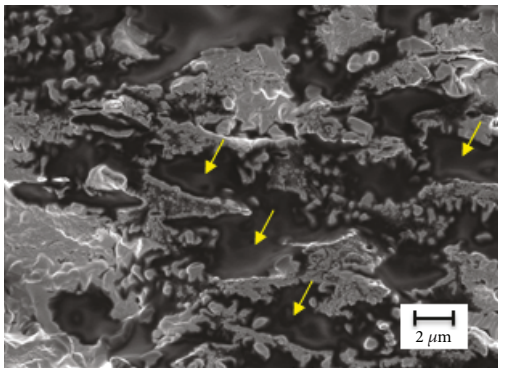

(e)

FIGURE 3: Scanning electron microscopy (SEM) images of the fracture surface of alginate films incorporating various CEO-NE concentrations viewed at a magnification of 5000x: (a) control, (b) CEO-NE 20\%, (c) CEO-NE 25\%, (d) CEO-NE 30\%, and (e) CEO-NE 40\%. Arrows show cavity-like structures in the film matrix.

TABLE 2: Optical properties $(L, a, b$, and $\Delta E)$ and moisture content of the control and CEO-NE-alginate films. Different letters in the same column indicate significant differences at $p<0.05$ by the ANOVA test. ${ }^{*}$ The percentages indicate the amount of nanoemulsion incorporated into the films $(\%, v / w)$, based on total film-forming solution. Control = pure alginate film.

\begin{tabular}{lccccc}
\hline \multirow{2}{*}{ Films } & $L$ & $a$ & $b$ & $\Delta E$ & Moisture content (\%) \\
\hline Control & $40.58 \pm 0.33^{\mathrm{d}}$ & $0.46 \pm 0.06^{\mathrm{d}}$ & $0.54 \pm 0.06^{\mathrm{a}}$ & $13.59 \pm 0.09^{\mathrm{a}}$ & $12.11 \pm 0.44^{\mathrm{b}}$ \\
CEO-NE 20\%* & $39.18 \pm 0.78^{\mathrm{c}}$ & $0.07 \pm 0.04^{\mathrm{c}}$ & $1.48 \pm 0.34^{\mathrm{a}, \mathrm{b}}$ & $14.28 \pm 0.23^{\mathrm{a}, \mathrm{b}}$ & $10.18 \pm 0.19^{\mathrm{a}}$ \\
CEO-NE 25\% & $38.26 \pm 0.59^{\mathrm{b}}$ & $-0.30 \pm 0.17^{\mathrm{b}}$ & $2.97 \pm 0.66^{\mathrm{b}, \mathrm{c}}$ & $15.66 \pm 0.69^{\mathrm{b}, \mathrm{c}}$ & $10.69 \pm 0.26^{\mathrm{a}}$ \\
CEO-NE 30\% & $36.76 \pm 0.17^{\mathrm{a}}$ & $-0.47 \pm 0.21^{\mathrm{a}, \mathrm{b}}$ & $3.43 \pm 1.63^{\mathrm{c}}$ & $16.13 \pm 1.64^{\mathrm{c}, \mathrm{d}}$ & $12.27 \pm 1.54^{\mathrm{b}}$ \\
CEO-NE 40\% & $36.49 \pm 0.43^{\mathrm{a}}$ & $-0.72 \pm 0.14^{\mathrm{a}}$ & $4.75 \pm 0.53^{\mathrm{c}, \mathrm{d}}$ & $17.30 \pm 0.52^{\mathrm{d}}$ & $12.95 \pm 0.12^{\mathrm{b}}$ \\
\hline
\end{tabular}

TABLE 3: Antibacterial activities of the control and CEO-NE-alginate films. Different letters in the same row indicate significant differences at $p<0.05$ by the ANOVA test. * The percentages indicate the amount of nanoemulsion incorporated into the films (\%, $v / w)$, based on total filmforming solution. Control = pure alginate film.

\begin{tabular}{|c|c|c|c|c|c|}
\hline & \multicolumn{5}{|c|}{ Inhibition zone (mm) } \\
\hline & Control & CEO-NE $20 \% *$ & CEO-NE $25 \%$ & CEO-NE $30 \%$ & CEO-NE $40 \%$ \\
\hline \multicolumn{6}{|l|}{ Gram negative } \\
\hline S. typhimurium & $00.00 \pm 0.00^{\mathrm{a}}$ & $53.00 \pm 1.00^{\mathrm{b}}$ & $56.33 \pm 3.79^{\mathrm{b}}$ & $64.67 \pm 1.15^{\mathrm{c}}$ & $65.67 \pm 2.08^{\mathrm{c}}$ \\
\hline E. coli & $00.00 \pm 0.00^{\mathrm{a}}$ & $29.67 \pm 1.53^{\mathrm{b}}$ & $33.00 \pm 2.00^{\mathrm{c}}$ & $38.33 \pm 2.08^{\mathrm{d}}$ & $45.67 \pm 2.08^{\mathrm{e}}$ \\
\hline L. monocytogenes & $00.00 \pm 0.00^{\mathrm{a}}$ & $18.00 \pm 0.00^{\mathrm{b}}$ & $19.33 \pm 0.58^{\mathrm{c}}$ & $26.33 \pm 0.58^{\mathrm{d}}$ & $29.00 \pm 1.00^{\mathrm{e}}$ \\
\hline \multicolumn{6}{|l|}{ Gram positive } \\
\hline B. cereus & $00.00 \pm 0.00^{\mathrm{a}}$ & $31.00 \pm 2.65^{\mathrm{b}}$ & $42.33 \pm 2.08^{c}$ & $55.67 \pm 2.52^{\mathrm{d}}$ & $62.67 \pm 2.08^{\mathrm{e}}$ \\
\hline S. aureus & $00.00 \pm 0.00^{\mathrm{a}}$ & $34.67 \pm 2.08^{\mathrm{b}}$ & $36.00 \pm 2.00^{\mathrm{b}}$ & $44.67 \pm 2.52^{\mathrm{c}}$ & $48.67 \pm 1.53^{\mathrm{d}}$ \\
\hline S. mutans & $00.00 \pm 0.00^{\mathrm{a}}$ & $19.67 \pm 1.15^{\mathrm{b}}$ & $24.67 \pm 0.58^{c}$ & $31.00 \pm 2.00^{\mathrm{d}}$ & $37.33 \pm 2.52^{\mathrm{e}}$ \\
\hline
\end{tabular}



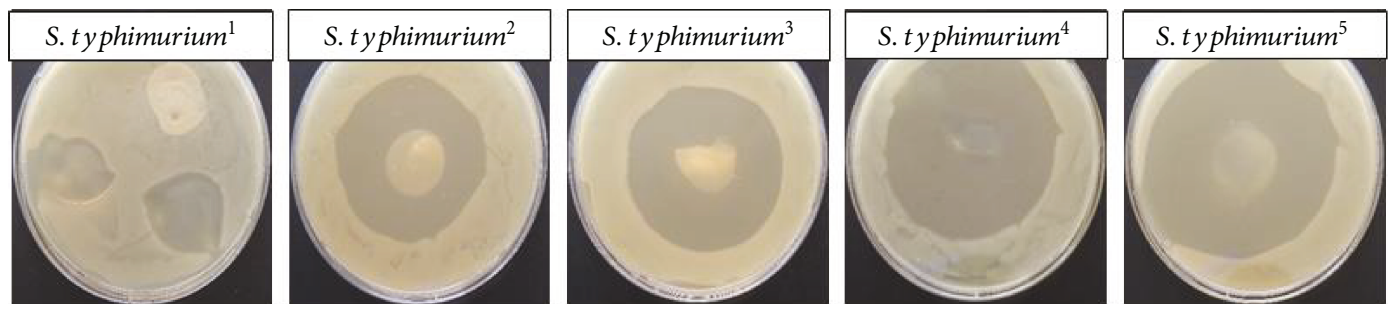

(a)
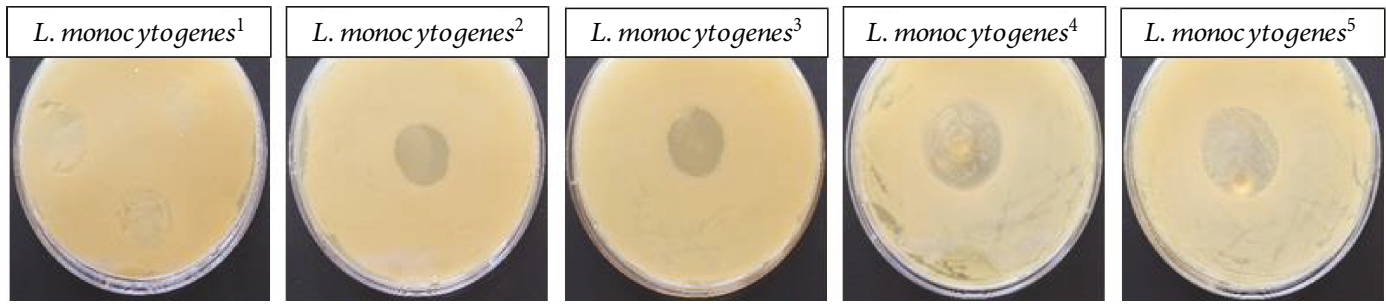

(b)

FIgure 4: Images of inhibition zones of CEO-NE-alginate films against (a) S. typhimurium and (b) L. monocytogenes, showing the largest and smallest halos, respectively, among tested bacteria. Films incorporating various CEO-NE concentrations were tested: (1) control, (2) CEO-NE 20\%, (3) CEO-NE 25\%, (4) CEO-NE 30\%, and (5) CEO-NE 40\%.

well as the more sustained release of the volatile compounds embedded in the polymer.

The antibacterial activity observed against E. coli agrees with the previous study [7] in which cinnamon oil and cinnamaldehyde were incorporated into alginate-based edible coats. Nevertheless, the application of the edible coats loaded with essential oil to cut apple resulted in changes to the sensory properties of the fruit, particularly when the oil was added at high concentrations; thus, the evaluation of the developed films using actual foods would also be necessary.

\section{Conclusions}

The manufactured CEO-NE/alginate biocomposite films containing cinnamon essential oil nanoemulsions (CEONEs) demonstrated strong antibacterial activity against both Gram-positive and Gram-negative bacteria. Increasing the oil concentration did not significantly affect the physical and mechanical properties of the biocomposite films, which is advantageous because high concentrations of essential oils are required to achieve substantial antibacterial effects in food applications. Therefore, the biocomposite films developed here have the potential to be used as active films in several food packaging applications.

\section{Data Availability}

The data used to support the findings of this study are available from the corresponding author upon request.

\section{Conflicts of Interest}

The authors declare that there is no conflict of interest regarding the publication of this paper.

\section{Acknowledgments}

This research was supported by the Keimyung University Research Grant of 2016.

\section{References}

[1] J. Kerry and P. Butler, Eds., Smart Packaging Technologies for Fast Moving Consumer Goods, John Wiley \& Sons, Ltd, 2008.

[2] S. Pashova and V. Zhivkova, "Edible films and coatings used for prolonging the term of storage of foods," Forum Ware International, vol. 1, pp. 23-31, 2010.

[3] M. E. Embuscado and K. C. Huber, Eds., Edible Films and Coatings for Food Applications, Springer, 2009.

[4] B. D. Ulery, L. S. Nair, and C. T. Laurencin, "Biomedical applications of biodegradable polymers," Journal of Polymer Science Part B: Polymer Physics, vol. 49, no. 12, pp. 832-864, 2011.

[5] M. Maizura, A. Fazilah, M. H. Norziah, and A. A. Karim, "Antibacterial activity and mechanical properties of partially hydrolyzed sago starch-alginate edible film containing lemongrass oil," Journal of Food Science, vol. 72, no. 6, pp. C324C330, 2007.

[6] J. W. Rhim, "Physical and mechanical properties of water resistant sodium alginate films," LWT - Food Science and Technology, vol. 37, no. 3, pp. 323-330, 2004.

[7] R. M. Raybaudi-Massilia, M. A. Rojas-Graü, J. MosquedaMelgar, and O. Martín-Belloso, "Comparative study on essential oils incorporated into an alginate-based edible coating to assure the safety and quality of fresh-cut Fuji apples," Journal of Food Protection, vol. 71, no. 6, pp. 1150-1161, 2008.

[8] S. Burt, "Essential oils: their antibacterial properties and potential applications in foods-a review," International Journal of Food Microbiology, vol. 94, no. 3, pp. 223-253, 2004.

[9] S. Prabuseenivasan, M. Jayakumar, and S. Ignacimuthu, "In vitro antibacterial activity of some plant essential oils," BMC Complementary and Alternative Medicine, vol. 6, no. 1, p. 39, 2006. 
[10] C. Solans, P. Izquierdo, J. Nolla, N. Azemar, and M. GarciaCelma, "Nano-emulsions," Current Opinion in Colloid \& Interface Science, vol. 10, no. 3-4, pp. 102-110, 2005.

[11] T. Tadros, P. Izquierdo, J. Esquena, and C. Solans, "Formation and stability of nano-emulsions," Advances in Colloid and Interface Science, vol. 108-109, pp. 303-318, 2004.

[12] L. Salvia-Trujillo, M. A. Rojas-Graü, R. Soliva-Fortuny, and O. Martín-Belloso, "Effect of processing parameters on physicochemical characteristics of microfluidized lemongrass essential oil-alginate nanoemulsions," Food Hydrocolloids, vol. 30, no. 1, pp. 401-407, 2013.

[13] U. Buranasuksombat, Y. J. Kwon, M. Turner, and B. Bhandari, "Influence of emulsion droplet size on antimicrobial properties," Food Science and Biotechnology, vol. 20, no. 3, pp. 793800, 2011

[14] R. Severino, K. D. Vu, F. Donsì, S. Salmieri, G. Ferrari, and M. Lacroix, "Antimicrobial effects of different combined non-thermal treatments against Listeria monocytogenes in broccoli florets," Journal of Food Engineering, vol. 124, pp. 110,2014

[15] A. Acevedo-Fani, L. Salvia-Trujillo, M. A. Rojas-Graü, and O. Martín-Belloso, "Edible films from essential-oil-loaded nanoemulsions: physicochemical characterization and antimicrobial properties," Food Hydrocolloids, vol. 47, pp. 168-177, 2015.

[16] M. Jouki, N. Khazaei, M. Ghasemlou, and M. HadiNezhad, "Effect of glycerol concentration on edible film production from cress seed carbohydrate gum," Carbohydrate Polymers, vol. 96, no. 1, pp. 39-46, 2013.

[17] ASTM, Standard Test Method for Tensile Properties of Thin Plastic Sheeting. Standard D882, American Society for Testing and Materials, Philadelphia, PA, USA, 2001.

[18] B. C. Nzeako, Z. S. Al-Kharousi, and Z. Al-Mahrooqui, "Antimicrobial activities of clove and thyme extracts," Sultan Qaboos University Medical Journal, vol. 6, no. 1, pp. 3339, 2006.

[19] K. Kon and M. Rai, "Antibacterial activity of Thymus vulgaris essential oil alone and in combination with other essential oils," Nusantara Bioscience, vol. 4, pp. 50-56, 2012.

[20] Y. Pranoto, V. M. Salokhe, and S. K. Rakshit, "Physical and antibacterial properties of alginate-based edible film incorporated with garlic oil," Food Research International, vol. 38, no. 3, pp. 267-272, 2005.

[21] S. Shojaee-Aliabadi, H. Hosseini, M. A. Mohammadifar et al., "Characterization of $\kappa$-carrageenan films incorporated plant essential oils with improved antimicrobial activity," Carbohydrate Polymers, vol. 101, pp. 582-591, 2014.

[22] M. J. Fabra, R. Pérez-Masiá, P. Talens, and A. Chiralt, "Influence of the homogenization conditions and lipid selfassociation on properties of sodium caseinate based films containing oleic and stearic acids," Food Hydrocolloids, vol. 25, no. 5, pp. 1112-1121, 2011

[23] M. Ghasemlou, N. Aliheidari, R. Fahmi et al., "Physical, mechanical and barrier properties of corn starch films incorporated with plant essential oils," Carbohydrate Polymers, vol. 98, no. 1, pp. 1117-1126, 2013

[24] F. M. Pelissari, M. V. E. Grossmann, F. Yamashita, and E. A. G. Pineda, "Antimicrobial, mechanical, and barrier properties of cassava starch-chitosan films incorporated with oregano essential oil," Journal of Agricultural and Food Chemistry, vol. 57, no. 16, pp. 7499-7504, 2009.
[25] A. Aguirre, R. Borneo, and A. E. Leon, "Antimicrobial, mechanical and barrier properties of triticale protein films incorporated with oregano essential oil," Food Bioscience, vol. 1, pp. 2-9, 2013.

[26] P. R. Salgado, M. E. López-Caballero, M. C. Gómez-Guillén, A. N. Mauri, and M. P. Montero, "Sunflower protein films incorporated with clove essential oil have potential application for the preservation of fish patties," Food Hydrocolloids, vol. 33 , no. 1 , pp. $74-84,2013$.

[27] H. Tian, W. Wu, G. Guo, B. Gaolun, Q. Jia, and A. Xiang, "Microstructure and properties of glycerol plasticized soy protein plastics containing castor oil," Journal of Food Engineering, vol. 109, no. 3, pp. 496-500, 2012.

[28] L. Sánchez-González, A. Chiralt, C. González-Martínez, and M. Cháfer, "Effect of essential oils on properties of film forming emulsions and films based on hydroxypropylmethylcellulose and chitosan," Journal of Food Engineering, vol. 105, no. 2, pp. 246-253, 2011.

[29] S. Bouhdid, J. Abrini, M. Amensour, A. Zhiri, M. J. Espuny, and A. Manresa, "Functional and ultrastructural changes in Pseudomonas aeruginosa and Staphylococcus aureus cells induced by Cinnamomum verum essential oil," Journal of Applied Microbiology, vol. 109, no. 4, pp. 1139-1149, 2010. 


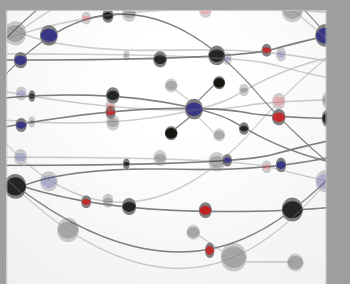

The Scientific World Journal
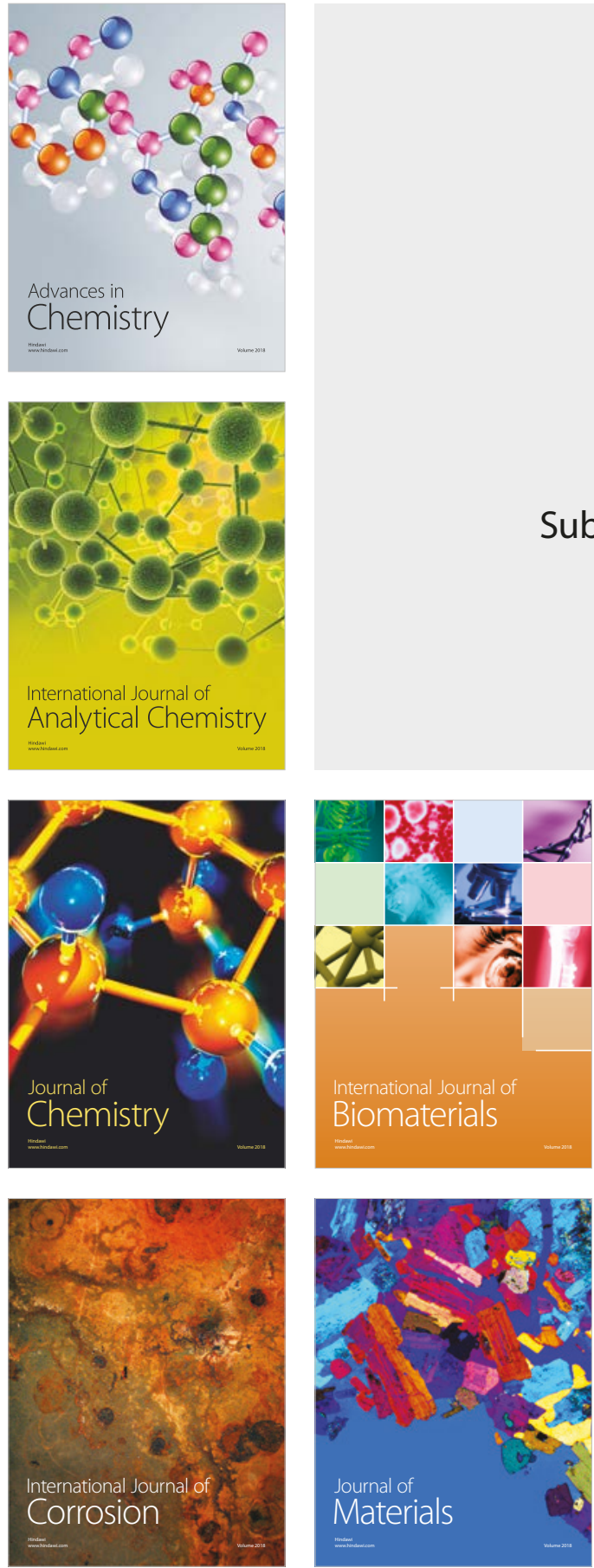

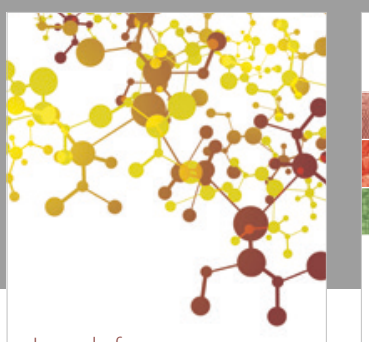

Journal of

Applied Chemistry
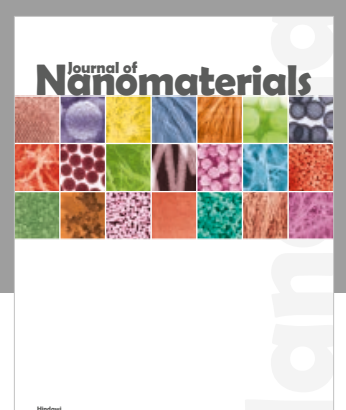

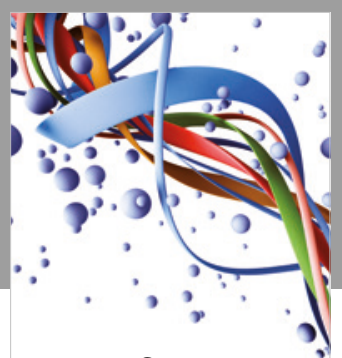

Scientifica

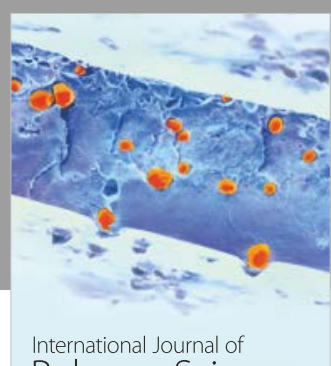

Polymer Science

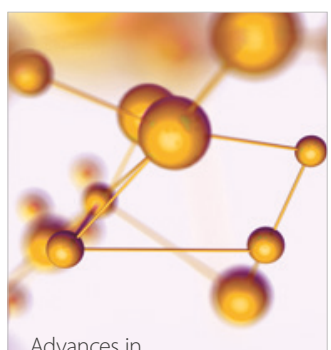

Physical Chemistry
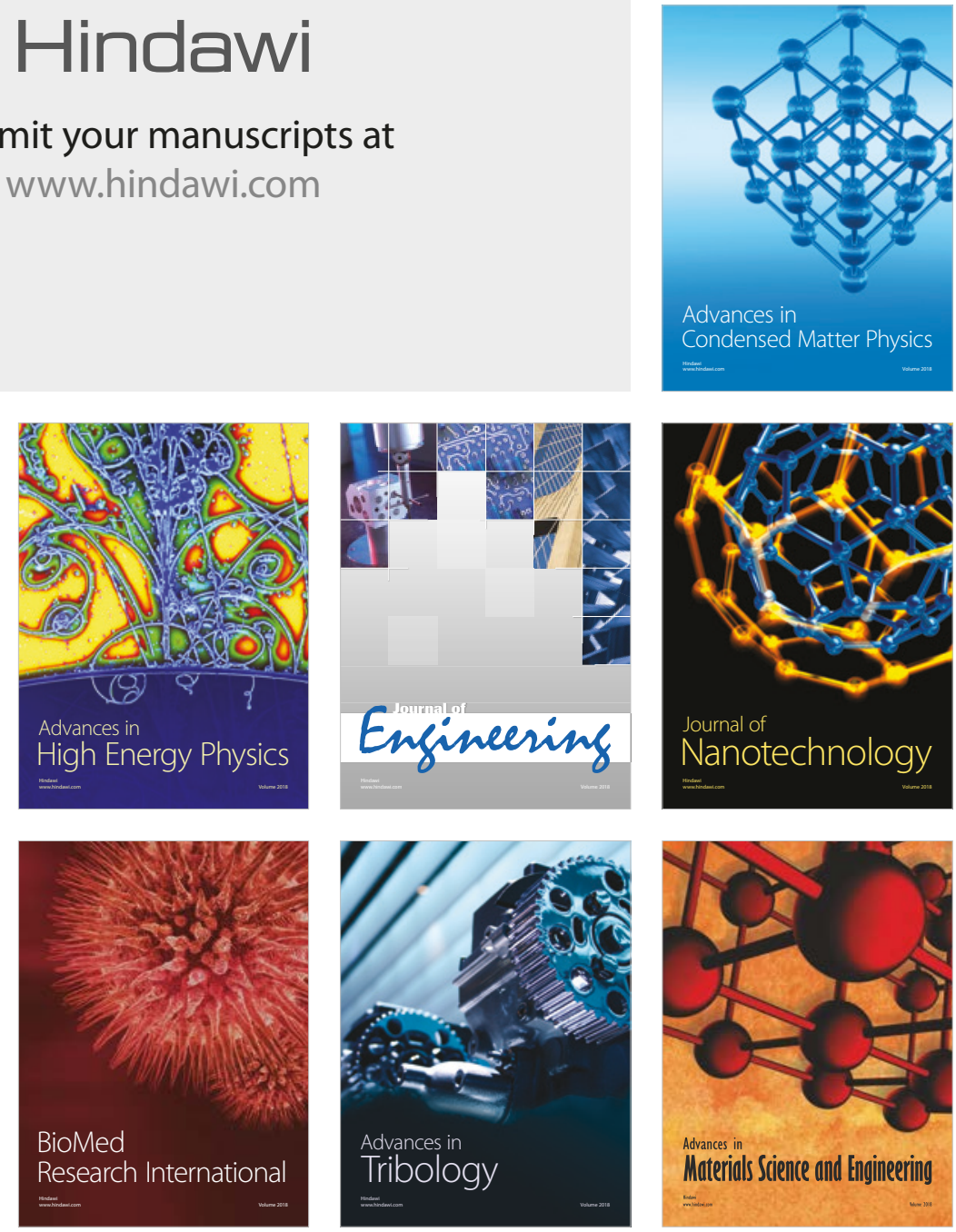